\title{
Management of a rare cause of significant acute upper gastrointestinal bleeding: gastric lipoma resected by hybrid endoscopic submucosal dissection
}

Gastric lipomas are rare, benign, slowgrowing subepithelial tumors. Most lipomas remain asymptomatic and are detected incidentally at endoscopy. Large lipomas, however, may very rarely cause significant upper gastrointestinal (GI) bleeding and warrant removal [1].

For the management of large gastric lipomas, laparoscopic excision may be required, but endoscopic techniques such as endoscopic submucosal dissection (ESD) and unroofing have also been described [1,2].

This endoscopic video case highlights this rare cause of upper Gl bleeding and its definitive management by hybrid ESD. A 66-year-old man presented with melena, pallor, and fatigue. On admission, his hemoglobin level was $89 \mathrm{~g} / \mathrm{L}$. He underwent an upper $\mathrm{Gl}$ endoscopy during which a $3 \mathrm{~cm}$ ulcerated submucosal lesion was identified at the greater curvature ( $\mathbf{F i g . 1}$ ). An endoscopic clip and Hemospray (Cook Medical, Winston-Salem, North Carolina, USA) were applied, and hemostasis was achieved.

Computed tomography imaging revealed an ovoid (fat-dense) lesion measuring $25 \times 15 \mathrm{~mm}$, consistent with a lipoma ( $\triangleright$ Fig.2). Endoscopic ultrasound assessment of the lesion was subsequently performed, and showed the presence of

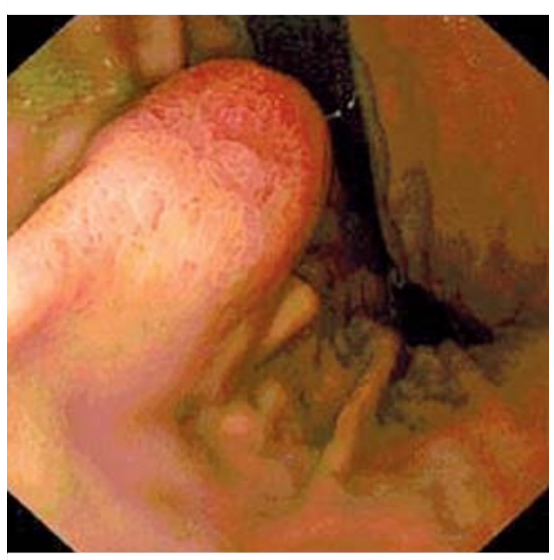

>Fig. 1 Gastric lipoma. a homogeneous and slightly hyperechoic lesion, $25 \times 15 \mathrm{~mm}$, arising from the hyperechoic submucosal layer. A $22 \mathrm{~g}$ needle was used to obtain core biopsies but

unfortunately the sample was inadequate for diagnostic assessment.

Endoscopic management of the lesion was agreed and the lesion was success-

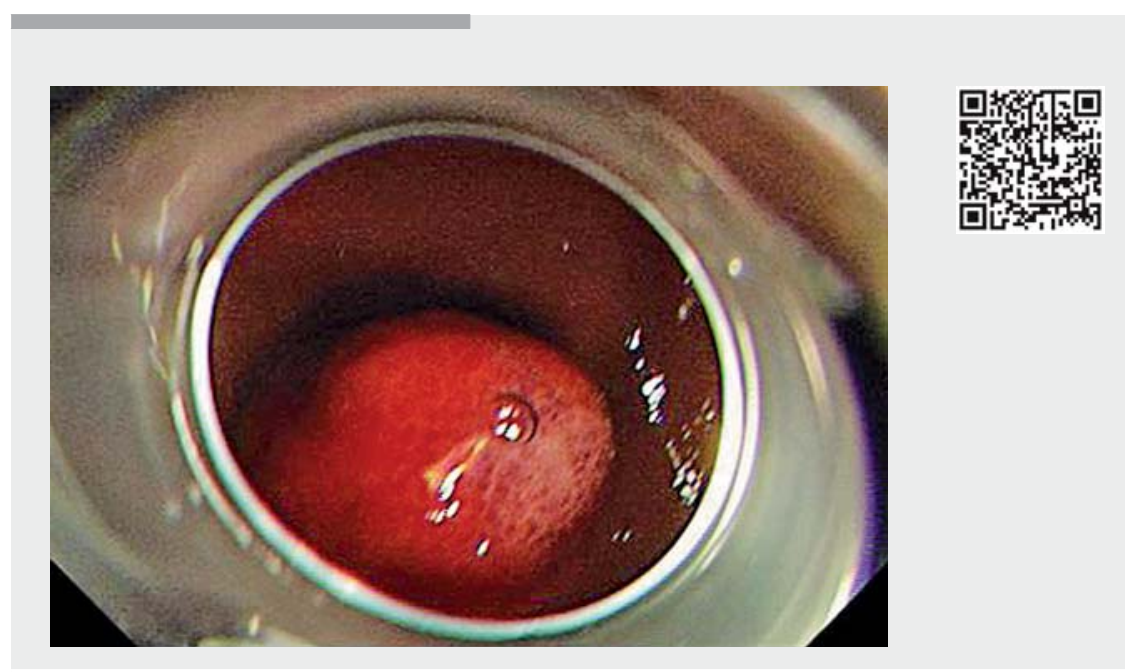

$\checkmark$ Video 1 Hybrid endoscopic submucosal dissection procedure for the endoscopic management of a gastric lipoma.

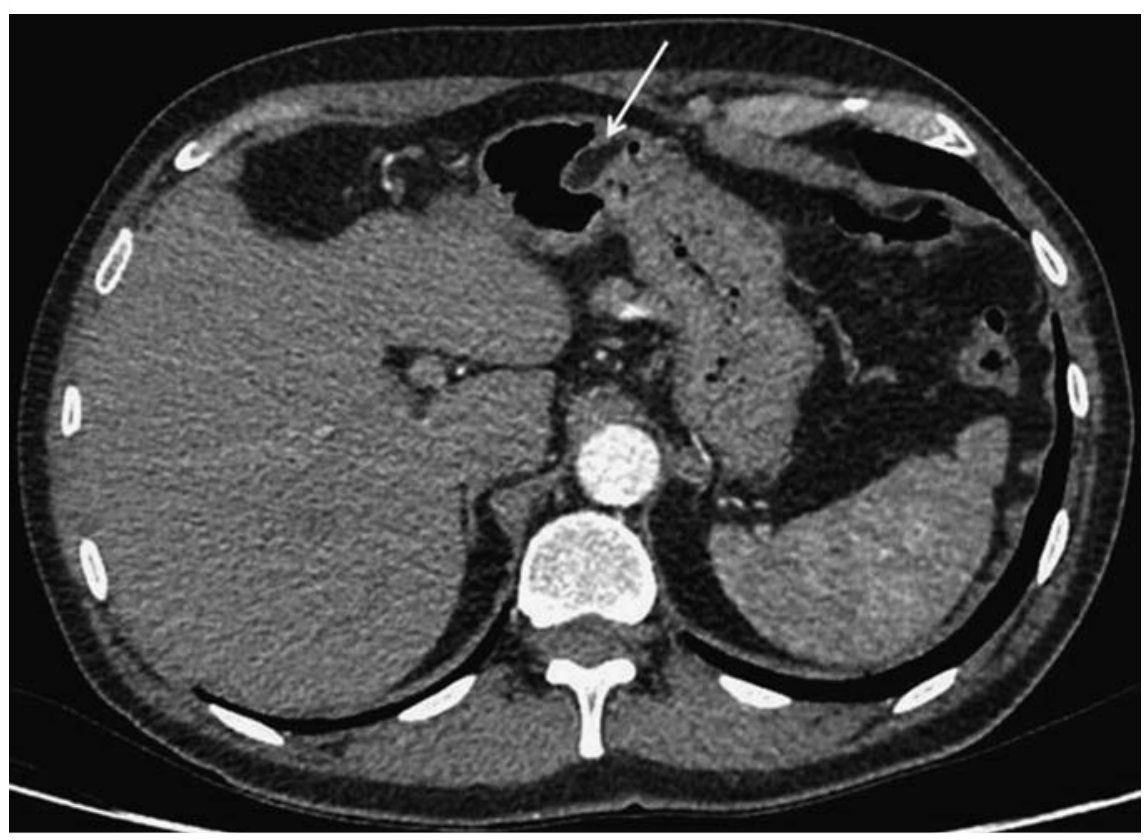

Fig. 2 Abdominal computed tomography scan image: white arrow points to gastric lipoma. 


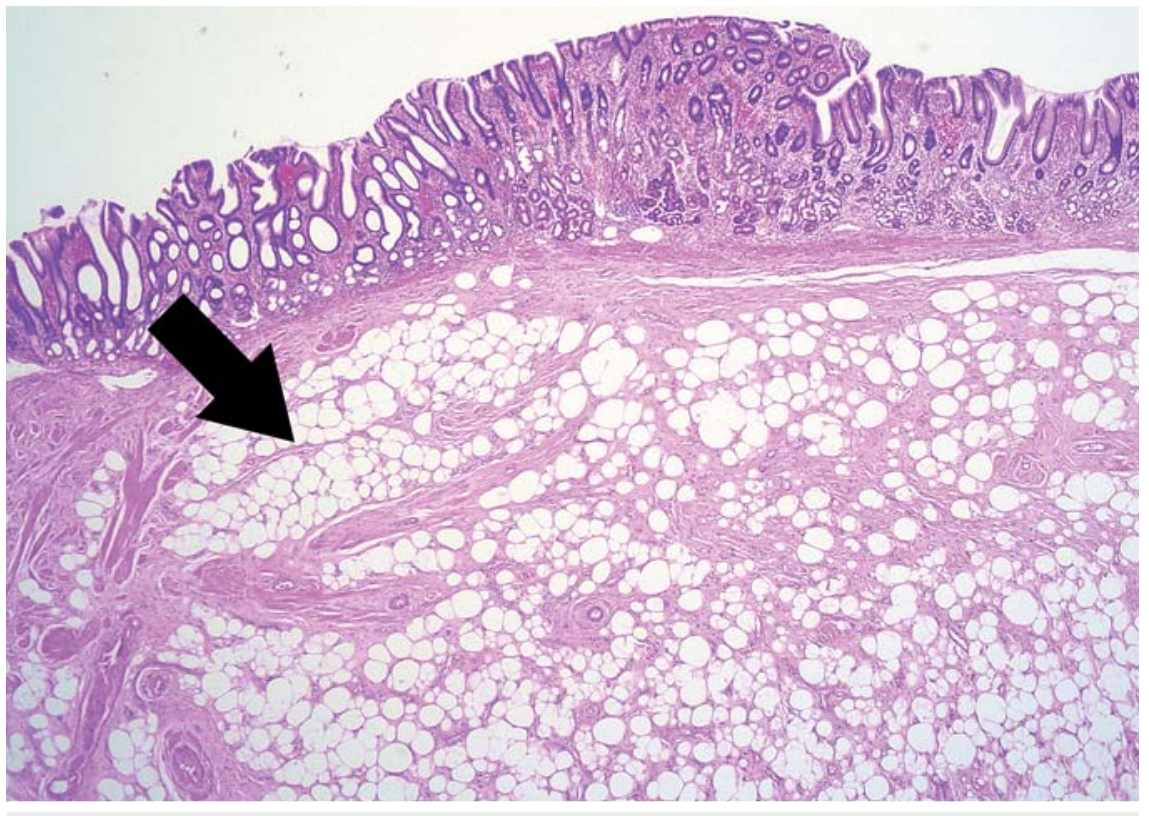

Fig. 3 Histopathology revealed submucosal gastric lipoma. The arrow indicates the fatty tissue of the lipoma.

fully resected by hybrid ESD ( $\vee$ Video 1 ). No immediate or delayed adverse events were encountered.

Histopathology confirmed the diagnosis of submucosal gastric lipoma, which was completely excised ( $>$ Fig. $\mathbf{3}$ ). On repeat endoscopy 3 months post-procedure, a well-healed scar was seen at the site of excision.

This video case highlights the role of hybrid ESD in the minimally invasive and definitive management of this rare submucosal cause of upper GI bleeding.

Endoscopy_UCTN_Code_TTT_1AO_2AG

\section{The Authors}

Nikolaos Koukias ${ }^{1}$, Alberto Murino', Andrea Telese ${ }^{1}$, Laura Gaeta ${ }^{1}$, Niall Power ${ }^{2}$, Michael Rathbone $^{3}$, Edward J. Despott ${ }^{1}$

1 Royal Free Unit for Endoscopy, The Royal Free Hospital and University College London (UCL) Institute for Liver and Digestive Health, London, United Kingdom

2 Depatment of Radiology, The Royal Free Hospital and UCL Institute for Liver and Digestive Health, London, United Kingdom

3 Academic Department of Cellular Pathology, The Royal Free Hospital and UCL Institute for Liver and Digestive Health, London, United Kingdom
Corresponding author

\section{Edward J. Despott, MD}

The Royal Free Hospital and University College London Institute for Liver and Digestive Health, Pond St., Hampstead, London NW3 2QG, United Kingdom Fax: +44-207-4315261

edespott@doctors.org.uk

\section{References}

[1] Lee KJ, Kim GH, Park DY et al. Endoscopic resection of gastrointestinal lipomas: a single-center experience. Surg Endosc 2014; 28: $185-192$

[2] Matsushita M, Fukata N, Okazaki K. Endoscopic removal of large gastric lipomas: en bloc resection with submucosal dissection or partial resection with unroofing technique? Dig Endosc 2013; 25: 211-212

\section{Bibliography}

DOI https://doi.org/10.1055/s-0043-115002

Published online: 18.7.2017

Endoscopy 2017; 49: E246-E247

(c) Georg Thieme Verlag KC

Stuttgart · New York

ISSN 0013-726X

\section{ENDOSCOPY E-VIDEOS}

https://eref.thieme.de/e-videos

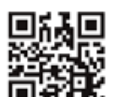

Endoscopy E-Videos is a free access online section, reporting on interesting cases and new

techniques in gastroenterological endoscopy. All papers include a high quality video and all contributions are freely accessible online.

This section has its own submission website at https://mc.manuscriptcentral.com/e-videos 